\title{
PHOTOCATALYTIC DEGRADATION OF TRICHLOROETHYLENE OVER SILVER NANOPARTICLES SUPPORTED ON $\mathrm{TIO}_{2}$
}

\author{
C. MALDONADO', J.L.G. FIERRO', J. CORONADO ${ }^{3}$, B. SÁNCHEZ ${ }^{4}$ P. REYES ${ }^{\prime *}$ \\ ${ }^{1}$ Facultad de Ciencias Quimicas, Universidad de Concepción, Chile. \\ ${ }_{2}^{2}$ Instituto de Catálisis y Petroleoquímica (CSIC), Madrid, Spain. \\ ${ }^{3}$ IMDEA-Energía, Unidad de Procesos Termoquímicos, Móstoles, Madrid, Spain. \\ ${ }^{4}$ Laboratorio de Aplicaciones ambientales de la Energía Solar en aire, CIEMAT, Spain.
}

(Received: May 17, 2010 - Accepted: August 10, 2010)

\begin{abstract}
The photocatalytic degradation of trichloroethylene over Ag nanoparticles supported on $\mathrm{TiO}_{2}$, was studied. The photocatalysts were obtained by impregnation of $\mathrm{Ag}$ colloids on $\mathrm{TiO}_{2}$. They were characterized by XPS, TEM and UV-vis. $\mathrm{Ag}^{0}$ nanoparticles were obtained with diameters between $2.0-3.2 \mathrm{~nm}$. The photocatalysts were found to display band gap energies similar to those of pure $\mathrm{TiO}_{2}$, although the presence of $\mathrm{Ag}$ nanoparticles results in the formation of a plasmon resonance band in the visible range. The photocatalytic activity of the $\mathrm{Ag} / \mathrm{TiO}_{2}$ samples to remove trichlorethylene (TCE) in gas phase was tested. With visible light, up to $60 \%$ of conversion was obtained.
\end{abstract}

\section{INTRODUCTION}

Trichloroethylene (TCE) is a volatile organic compound widely used to manufacture paints, disinfectants, varnishes, adhesives, dry cleaning, etc., where dry cleaning is the application with the greatest TCE presence. Due to its use, TCE is now a contaminant of groundwater, surface and soil. Constant exposure to TCE is associated with pathological and toxicological problems, causing disturbances in the central nervous system and liver and kidney problems. TCE has produced hepatic lipid peroxidation and elevated oxidation of DNA in mice [1]. Since TCE is the most common halogenated pollutant found in groundwater and is a threat to human health, TCE degradation needs to be studied.

Semiconductors have shown excellent properties as photocatalysts, among them those based on $\mathrm{TiO}_{2}$ and doped $\mathrm{TiO}_{2}$ are specially relevant [2-7]. Since the 1990 s, many studies have used $\mathrm{TiO}_{2}$ photocatalyst to degrade TCE to $\mathrm{CO}_{2}$ and $\mathrm{HCl}$ [8-12]. The effect of $\mathrm{ZnO}, \mathrm{Pt}, \mathrm{Pd}, \mathrm{Cr}, \mathrm{Fe}, \mathrm{Ni}, \mathrm{Cu}, \mathrm{CdS}$ and silica gel over $\mathrm{TiO}_{2}$ photocatalyst has been studied on photocatalytic degradation of TCE [1316]. However, only a few studies of the photocatalytic activity of nanoparticles supported on $\mathrm{TiO}_{2}$ have been reported. Ag clusters present several advantages, including that they exhibit visible light absorption due to surface plasmon resonance [17-19]. This very relevant feature of a photocatalysts allows them to contribute to a better use of solar radiation, enhancing the environmental value of the process.

The main aim of the present research was to study the effect of $\mathrm{Ag}$ nanoparticles supported on $\mathrm{TiO}_{2}$ on the photocatalytic degradation of TCE. Several procedures has been developed to prepare metal nanoparticles [20-22]. $\mathrm{Ag}$ nanoparticles were prepared by the reduction of an aqueous solution of $\mathrm{AgNO}_{3}$ with $\mathrm{HCOOH}$ under mild conditions and then the colloidal dispersion impregnated on a $\mathrm{TiO}_{2}$ support. A series of $\mathrm{Ag} / \mathrm{TiO}$, catalysts with different $\mathrm{Ag}$ loadings were prepared and the solids were characterized by TEM, XPS and UV-Vis studies. The TCE was degraded in a flow reactor, and the obtained results indicate that the photocatalytic degradation of TCE has been substantially improved by the incorporation of $\mathrm{Ag}$ nanoparticles on $\mathrm{TiO}_{2}[5]$.

\section{EXPERIMENTAL}

\subsection{Preparation of the photocatalysts}

Photocatalysts were prepared by wet impregnation of the support $\left(\mathrm{TiO}_{2}\right.$ P 25 DEGUSSA, $72 \mathrm{~m}^{2} \mathrm{~g}^{-1}$ ) at $\mathrm{pH} 5$ with a silver colloidal dispersion, in appropriate amount to obtain Ag loading of 0.1-0.9 wt.\%. Ag colloids were prepared by reduction of an aqueous solution of $\mathrm{AgNO}_{3}$ (ARQUIMED) mixed with a $0.10 \mathrm{M}$ solution of $\mathrm{HCOOH}$ (MERCK) under continuous stirring, which was maintained under reflux at $373 \mathrm{~K}$ for $1 \mathrm{~h}$ [23-25].Then, the colloid dispersion was cooled down and it was impregnated on the support

\subsection{Characterization}

X-ray photoelectron spectra were obtained with a VG ESCALAB 200R spectrometer (VG-Scientific). The binding energies Ag $3 \mathrm{~d}_{5 / 2}$ and $3 \mathrm{~d}_{3 / 2}$, Ti $2 \mathrm{p}_{3 / 2}$ and $\mathrm{O} 1 \mathrm{~s}$ were analyzed. The TEM micrographs were obtained from a Jeol equipment, model JEM-1200 EXII. UV-Visible spectra of the photocatalysts were obtained using a Cary 5000 spectrophometer. The Band Gap was obtained from UV-visible spectra [26].

\subsection{Photocatalytic activity}

The photocatalytic activity tests were conducted in a continuous flow flat reactor with a Pyrex glass window and an illuminated area of $27 \mathrm{~cm}^{2}$ as described in detail in previous works [5]. Two kinds of UV lamps were set in a window: 1) a Philips TL-8W/05that shows a maximum emission at $365 \mathrm{~nm}$ or 2) a "daylight" Osram L8W/954 that approximately reproduces the solar spectrum. In the latter case, in some experiments, a polyester filter (Edmund Optics) was also used in order to remove the small contribution of the ultraviolet fluorescence and to ensure that the activity observed corresponds only to activation in the visible region $(\lambda>390 \mathrm{~nm})$.

The photocatalysts were deposited $(50-60 \mathrm{mg})$, as a relatively homogeneous film from a suspension in isopropanol, over a conventional microscope slide glass. The gas flow composition was established using mass flow controllers (MFC); it was mixed in the right proportions to obtain a concentration of 90 $\mathrm{ppm}$ of the pollutant in air. The mixture was prepared from an air flow (Atlas Copco), free of $\mathrm{CO}_{2}$ and humidity, and a synthetic mixture containing $500 \mathrm{ppm}$ of Trichloroethylene in $\mathrm{N}_{2}$ (L'Air Liquide).

The pollutant and reaction products were detected using a FTIR ThermoNicolet 5700 spectrometer, equipped with a cell of multiple reflection gases (2-meter optical path) and a DTGS detector. The spectra were recorded by accumulating 64 scans at $4 \mathrm{~cm}^{-1}$ resolution.

\section{RESULTS AND DISCUSSION}

\subsection{X-ray Photoelectron Spectroscopy (XPS)}

XPS studies were performed to evaluate surface composition of the catalysts. There results showed the typical energies of $\mathrm{Ag} 3 \mathrm{~d}$, Ti $2 \mathrm{p}$ and $\mathrm{O} 1 \mathrm{~s}$. The O 1s core-level peaks at 529.9 and $531.4 \mathrm{eV}$ are attributed to $\mathrm{O} 1 \mathrm{~s}$ of Ti$\mathrm{O}-\mathrm{Ti}$ and $\mathrm{Ti}-\mathrm{OH}$ bonds [27] whereas $\mathrm{Ti} 2 \mathrm{p}_{32}$ level exhibits only one component centered at $458.5 \mathrm{eV}$, assigned to $\mathrm{Ti}^{+4}$ species [28]. The XP spectra of the $\mathrm{Ag}$ $3 \mathrm{~d}$ core level are shown in Figure 1, and the binding energies are reported in Table 1. The binding energies of the $\mathrm{Ag} 3 \mathrm{~d}_{5 / 2}$ peaks range from $367.9-368.1 \mathrm{eV}$, indicating that there is only one oxidation state corresponding to metallic silver [29]. It can also be seen that the $\mathrm{Ag} / \mathrm{Ti}$ atomic relation increases linearly with the metal content. This behavior indicates that the metal dispersion is very similar for all photocatalysts. The Ag/Ti surface ratio was evaluated by XPS, however, the low signal of the samples with lower metal content $(0.1$ and 0.3 $\mathrm{wt} \%$ ) do not allowed an estimation of $\mathrm{Ag} / \mathrm{Ti}$ ratio. 


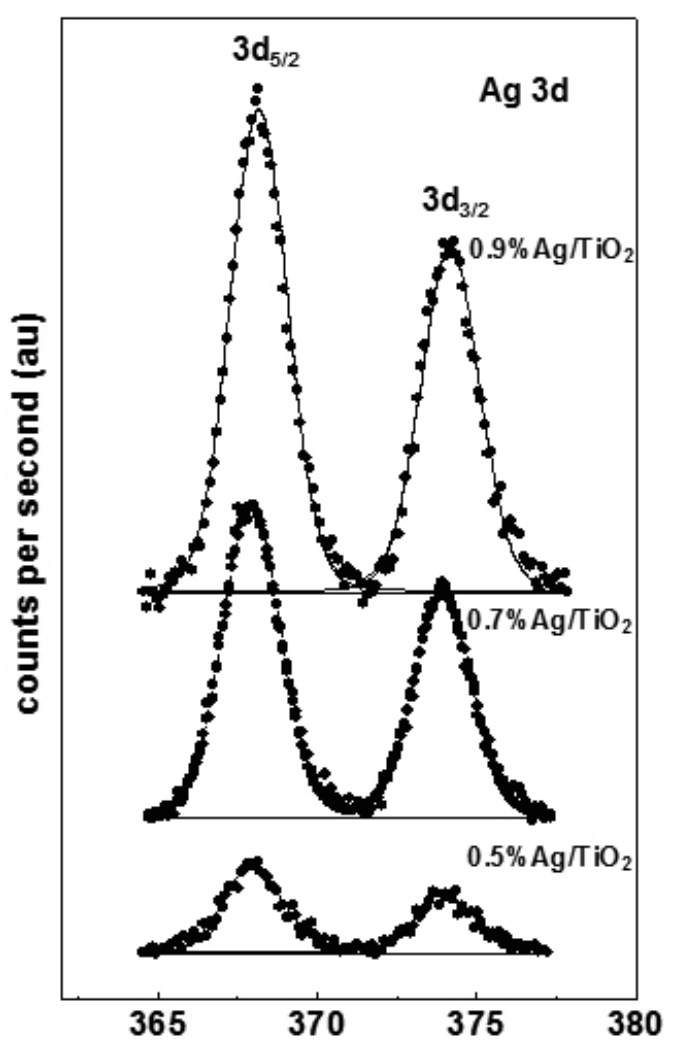

Fig 1: XPS spectra of $\mathrm{Ag} 3 \mathrm{~d}_{5 / 2}$ and $3 \mathrm{~d}_{3 / 2}$ of $\mathrm{Ag} / \mathrm{TiO}_{2}$ catalysts.

Table 1: Binding energy of $\mathrm{Ag} 3 \mathrm{~d}_{5,2}$ and $\mathrm{Ti} 2 \mathrm{p}_{3,2}$ core level $(\mathrm{eV})$ and $\mathrm{Ag} /$ $\mathrm{Ti}$ atomic surface ratio obtained by XPS and metal particle size of $\mathrm{Ag} / \mathrm{TiO}_{2}$ catalysts.

\begin{tabular}{|c|c|c|c|c|c|}
\hline $\begin{array}{l}\text { Ag loading, } \\
\text { wt } \%\end{array}$ & $\underset{\mathrm{eV}}{\mathrm{Ag} \mathrm{3d_{5/2 }}}$ & $\begin{array}{c}\text { Ti } 2 \mathrm{p}_{3 / 2} \\
\mathrm{eV}^{-2}\end{array}$ & $\begin{array}{l}\mathrm{O} 1 \mathrm{~s} \\
\mathrm{eV}\end{array}$ & $\begin{array}{c}\mathrm{Ag} / \mathrm{Ti} \\
\text { atom/atom }\end{array}$ & $\begin{array}{l}d_{n m} \\
\text { TEM }\end{array}$ \\
\hline \multirow[t]{2}{*}{0,5} & 368.0 & 458.6 & $529.9(83)$ & 0.005 & 2.0 \\
\hline & & & $531.4(17)$ & & \\
\hline \multirow[t]{2}{*}{0,7} & 367.9 & 458.5 & $529.9(85)$ & 0.019 & 2.2 \\
\hline & & & $531.4(15)$ & & \\
\hline \multirow[t]{2}{*}{0,9} & 368.1 & 458.5 & $529.9(84)$ & 0.028 & 3.2 \\
\hline & & & $531.4(16)$ & & \\
\hline
\end{tabular}

\subsection{Transmission electron microscopy (TEM)}

TEM studies were used to estimate metal particle size. Figure 2 shows a representative micrograph as well as the metal particle size distribution for one of the studied catalysts, the nanoparticles are observed to be in the range 0.5$5.0 \mathrm{~nm}$ with a rather narrow distribution. It should be mentioned that more than 500 particles from different micrographs were evaluated in order to obtain the distribution. The catalysts with a lower metal particle size display the smaller metal particle size and narrower distribution. Thus, catalysts with 0.1 to 0.5 $\mathrm{wt} \%$ display average metal particle size of $2.0 \mathrm{~nm}$ (and particles ranging from 0.8 to $3.0 \mathrm{~nm}$ ). The samples with higher metal loading $(0.7$ and $0.9 \mathrm{wt} \%)$ display an average particle size of 2.2 and $3.2 \mathrm{~nm}$ respectively, as well as a wider distribution ( 0.8 to $3.8 \mathrm{~nm}$ and 0.8 to $5.0 \mathrm{~nm}$ respectively). A summary of the observed particle sizes are given in Table 1. The increases in the metal particle size observed can be explained by the experimental procedure used to obtain metal nanoparticles. Thus, as the reduction species are formed $\left(\mathrm{H}_{2}\right)$, $\mathrm{Ag}^{+}$species are reduced to a zero valent state, forming small aggregates even when they remain in the colloidal dispersion and gradually are deposited onto the support. As the metal content increases, the formed nanoparticles remain longer in the colloidal dispersion and consequently the chance to grow is higher [30].
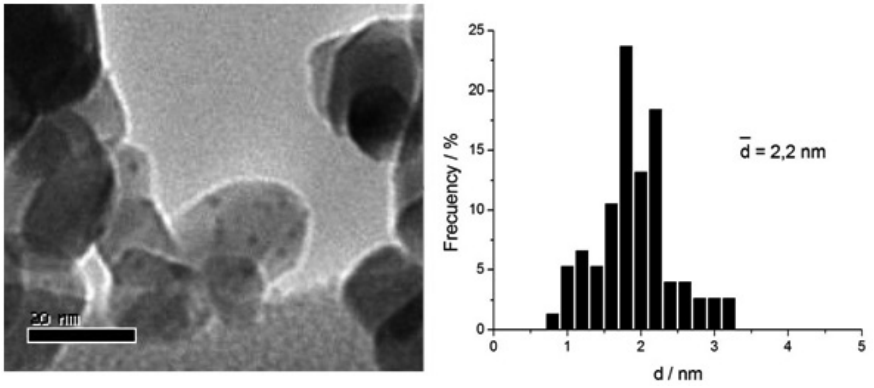

Fig 2: TEM micrographs and particle size distribution of photocatalysts of $\mathrm{Ag} / \mathrm{TiO}_{2}$ nanoparticles.

\subsection{UV-Visible spectra}

UV-visible light spectra for some of the $\mathrm{Ag} / \mathrm{TiO}_{2}$ samples are plotted in Figure 3. These results show that $\mathrm{Ag}$ nanoparticles give rise to a band in the visible range that grows and shifts to larger wavelengths with increases in the metal loading. These spectral features can be attributed to the plasmon resonance absorption, which for the case of $0.9 \% \mathrm{Ag} / \mathrm{TiO}_{2}$ is centered at 541 $\mathrm{nm}$. These absorptions can be associated with the light pink-violet color of the $\mathrm{Ag} / \mathrm{TiO}$, photocatalysts. Similar results have been previously obtained with other $\mathrm{Ag} / \mathrm{TiO}_{2}$ samples, although the band's exact position depends on nanoparticles' specific characteristics (i.e. shape, concentration...) [31].

On the other hand, the spectra of Figure 3 show that the absorption edge of $\mathrm{TiO}_{2}$ does not significantly change with the incorporation of Ag. Accordingly, bandgap values of 2.9-3.0 eV can be estimated from the electronic spectra for these photocatalysts, in agreement with other reports of $\mathrm{TiO}_{2}$-based photocatalysts [32].

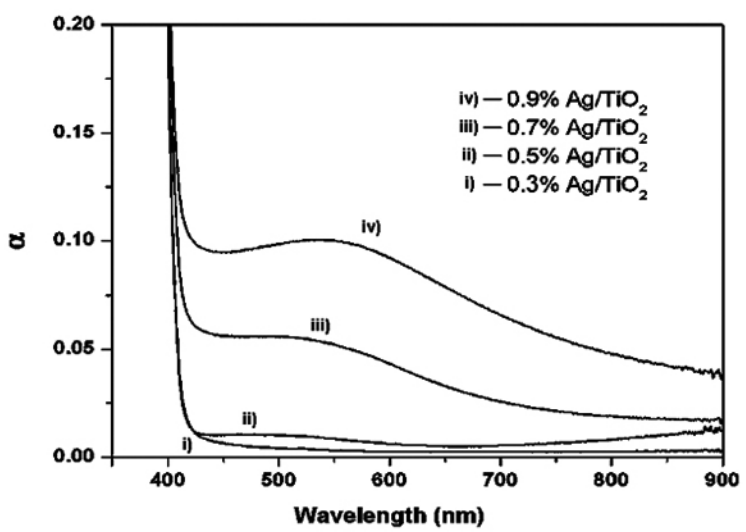

Fig 3: Diffuse reflectance UV-vis spectra of the $\mathrm{Ag} / \mathrm{TiO}_{2}$ photocatalysts.

\subsection{Catalytic activity}

The photocatalytic activity of the $\mathrm{Ag} / \mathrm{TiO}_{2}$ samples was tested to remove trichloroethylene (TCE) in gaseous phase. This halogenated compound has been widely used as a model pollutant because it provides a high sensitivity for activity measurement due to its high efficiency of photocatalytic degradation $[33,34]$.

However, under the given operating conditions (e.g., low residence times and low humidity), the reaction may favor the formation of various intermediates that can be even more toxic than the parent compound [33]. This is the case of phosgene, $\mathrm{COCl}_{2}$, which is formed in high concentrations in the absence of moisture according to the reaction

$$
\mathrm{CHCl}=\mathrm{CCl}_{2}+3 / 2 \mathrm{O}_{2}{ }^{\circledR} \mathrm{COCl}_{2}+\mathrm{CO}_{2}+\mathrm{HCl}
$$

For analytic simplicity, the experiments were performed under a dry air flow, and consequently a significant amount of phosgene was detected. Therefore, the results can be used to determine the photoactivity of the studied samples, although they do not indicate the full potential as an effective technology for removing volatile organic compounds. In this respect, it is worth noting that Jacoby et al. [35] showed that total photocatalytic mineralization of 
TCE can be achieved using longer residence times, relatively high humidity in the stream and additional catalysts beds in the dark for phosgene hydrolysis.

Figure 4 displays the evolution of TCE conversion as a function of gas flow for the different catalysts. As can be seen, all photocatalysts display a high activity, when they are irradiated with UV lamps. Thus, when the Flow/ area ratio is lower than $10 \mathrm{~cm}^{3} / \mathrm{min} / \mathrm{cm}^{2}$ of irradiated area, TCE conversion is higher than $93 \%$ for all catalysts. At higher Flow/ area ratios (and at lower residence times), conversion drops although the conversion levels are higher than $65 \%$ for the less active catalyst at Flow/ area ratio of 22.5. Similar trends were previously reported, although the catalyst activity reported here is higher [33].

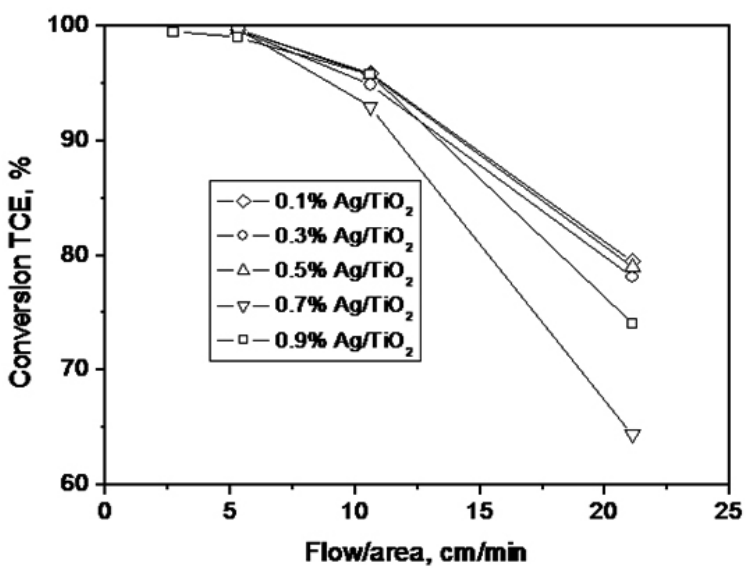

Fig 4: Conversion of TCE degradation vs flow / illuminated area ratio. UVA illumination and TCE 90ppm concentration.

Under UVA irradiation, all samples show similar photoactivity, although a slight decreasing tendency in conversion is observed with increasing $\mathrm{Ag}$ loading. These results are similar to those obtained by Young et al., indicating that small amounts of Ag enhance the catalytic activity but additional increases in Ag loading negatively affects the photocatalytic behavior [36].

When the catalysts are evaluated using simulated sunlight instead of UV, the samples are also very active. Fig. 5 compares the extent of TCE degradation for the different prepared catalysts under the same experimental conditions, i.e., a Flow/Area ratio of $5 \mathrm{~cm} / \mathrm{min}$ and a concentration of TCE of $90 \mathrm{ppm}$. The existence of an optimum Ag loading is more evident with simulated sunlight, and the degradation levels obtained are lower than those obtained with UV lamps, as expected. Sample with 0.3 to $0.7 \mathrm{wt} \% \mathrm{Ag}$ exhibit the best conversion levels, which are higher than $40 \%$. It is also important to note that simulated sunlight lamps emit a small, but non-negligible, UVA intensity. Therefore, considering the interest for semiconductor activation is present in the visible (for its use in solar applications), it is necessary to check whether $\mathrm{Ag} / \mathrm{TiO}$ photocatalysts can be activated using light with $\lambda>390 \mathrm{~nm}$ as the sole source of irradiation.

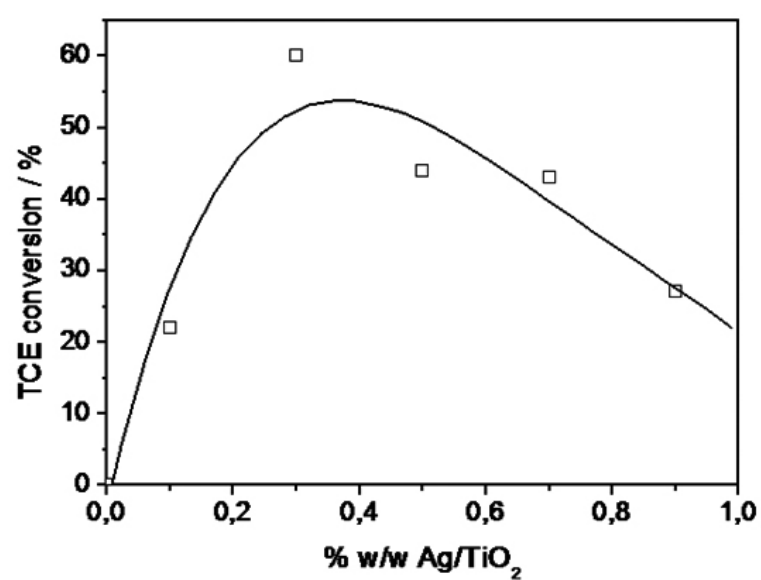

Fig 5: Conversion of TCE degradation at different metal loading over Ag/ $\mathrm{TiO}_{2}$ catalysts, under simulated sunlight. Flow/Area Ratio of $5 \mathrm{~cm} / \mathrm{min}$ and concentration of $90 \mathrm{ppm}$ TCE.

Figure 6 shows the evolution of TCE, $\mathrm{CO}_{2}$ and $\mathrm{HCl}$ concentration over time of irradiation with simulated sunlight on $0.3 \mathrm{wt} . \% \mathrm{Ag} / \mathrm{TiO}$. TCE removal efficiency under these conditions is approximately $30 \%$ and the mineralization is about $47 \%$. It is also important to point out that after reaching a steady state, at approximately 50 minutes, process conversion and selectivity remain stable. This fact suggests that $\mathrm{Ag}$ nanoparticles are not significantly modified by the halogenated products present in the reaction stream (e.g. $\mathrm{HCl})$. These data confirm that activation of the samples containing $\mathrm{Ag}$ is possible with visible light. However, considering the values of the band gap of $\mathrm{TiO}_{2}$, photon absorption is only possible in the metal nanoparticles. It is likely that visible light excites plasmonic mode of $\mathrm{Ag}$ particles, which could subsequently inject electrons into the conduction band of $\mathrm{TiO}_{2}$ [27]. In this way, electronic processes at the interface between Ag nanoparticles and the semiconductor could be significantly modified depending on the light wavelength.

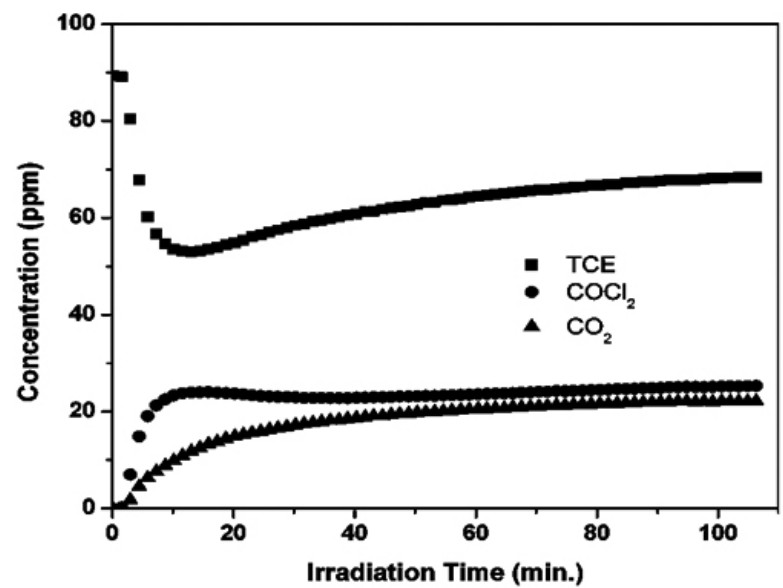

Fig 6: Evolution of concentration of TCE, $\mathrm{Cl}_{2}$ and $\mathrm{CO}_{2}$ as a function of irradiation time over $0.3 \% \mathrm{Ag} / \mathrm{TiO}$ catalyst. Conditions: flow $330 \mathrm{~cm}^{3} \mathrm{~min}^{-1}$ and initial concentration of $90 \mathrm{ppm}$ TCE.

Thus, under UV irradiation, Ag not only improves the photoactivity, but also the addition of high concentrations of this metal may be slightly negative, quite possibly due to centers of electron-hole recombination that are formed in the metal-oxide interface. However, with simulated sunlight, even when the overall efficiency decreases, the incorporation of $\mathrm{Ag}$ is clearly positive since the activation of the $\mathrm{TiO}_{2}$ through the UVA component emitted by the lamps is added to the activity in the visible created by sensitization with $\mathrm{Ag}$ nanoparticles, which allows the effective use of longer wavelength radiation. 


\section{CONCLUSIONS}

The obtained results have demonstrated the feasibility of using Ag nanoparticles supported on $\mathrm{TiO}_{2}$ as photocatalysts for the photochemical degradation of TCE in UV and visible light.

The physicochemical characterization of the photocatalysts shows that $\mathrm{Ag}^{0}$ nanoparticles are obtained with an average particle diameter of 2.0-3.2 nm, increasing the metal particle size with metal content. The incorporation of $\mathrm{Ag}$ nanoparticles on $\mathrm{TiO}_{2}$ is observed to result in a new absorption band in the visible due to plasmon resonance of the nanoparticles.

The photoactivity results indicate that the photocatalysts are highly active in TCE degradation; however, photoactivity decreases with increasing metal content over $0.7 \mathrm{wt} \%$ of $\mathrm{Ag}$. This fact is attributed to the formation of electron-hole recombination centers in the metal-oxide interface. Nevertheless, deposition of $\mathrm{Ag}$ nanoparticles on $\mathrm{TiO}_{2}$, allows TCE degradation using visible light until obtaining a $60 \%$ of conversion.

\section{REFERENCES}

[01] M. Seo, T. Yamagiwa, R. Kobayashi, K. Ikeda, M. Satoh, N. Inagaki, H. Nagai, H. Nagase, Reg. Toxicol. Pharmacol. 52, 130 (2008).

[02] K. Vinodgopal, S. Hotchandani, P.V. Kamat, J. Phys. Chem. 97, 9040 (1993).

[03] J. Cunningham, P.J. Sedlak, Photochem. Photobiol. A 77, 255 (1994).

[04] J.P. Wilcoxon, J. Phys. Chem. B 104, 7334 (2000).

[05] K. Jung, S. Park, Appl. Catal. B 25, 249 (2000).

[06] Y. Zhang, J. Crittenden, D. Hand, D. Perram, Environ. Sci. Technol. 28, 435 (1994).

[07] N. Arconada, A. Durán, S. Suárez, R. Portela, J.M. Coronado, B. Sánchez, Y. Castro, Appl Catal B: Environ 86, 1 (2009).

[08] R.M. Alberici, M.A. Mendes, W.F. Jardim, and M.N. Eberlin, J. Am. Soc. Mass Spectrom, 9, 1321 (1998).

[09] A. Jarandehei, M.K. Golpayegani, A. De Visscher, Appl. Catal. B: Environ. 84, 65 (2008).

[10] H.H. Ou, S.L. Lo, J. Haz. Mat. 146, 302 (2007).

[11] J.H. Jeon, S.D. Kim, T.H. Lim, D.H. Lee, Chemosphere 60, 1162 (2005).

[12] P.B. Amama, K. Itoh, M. Murabayashi, Appl. Catal. B: Environ. 37, 321(2002).
[13] M.D. Driessen, A.L. Goodman, V.H. Grassian, J. Phys. Chem. B 102, 549 (1998).

[14] A.A. Ismail, Appl Catal B: Environ 85, 33 (2008).

[15] H.H. Ou, S.L. Lo, J. Mol. Catal. A: Chem. 275, 200 (2007).

[16] T.H. Lim, S.D. Kim, Chemosphere 54, 305 (2004).

[17] Y. Cao, W.L. Dai, J.F. Deng, Appl. Catal. A, 158, L27 (1997) .

[18] H-Y Chuang and D-H Chen, Nanotech. 20, 105704 (2009).

[19] K. Awazu, M. Fujimaki, C. Rockstuhl, J. Tominaga, H. Murakami, Y. Ohki, N. Yoshida, and T. Watanabe, J. Am. Chem. Soc., 130, 1676 (2008

[20] D. Ruiz and P.Reyes, J. Chil. Chem. Soc. 53 (4), 1740 (2008).

[21] C.Urbina, G. Pecchi, C. Campos, P. Reyes' J. Chil. Chem. Soc. 55 (1), 25 (2010) .

[22] C. Urbina, C. Campos, G. Pecchi, C. Claver, P. Reyes Molecules, 15 3428 (2010).

[23] C. Quispe, J. Villaseñor G.Pecchi and P. Reyes, J.Chil.Chem.Soc. 51, 1049 (2006) .

[24] J. Villaseñor, P. Reyes, G.Pecchi, Catal. Today 76, 121 (2002).

[25] J. Villaseñor, H. Mansilla, J. Photochem. Photobiol: A Chem. 93, 205 (1996) .

[26] R.M. Navarro, F. del Valle, J.L.G. Fierro, Int. J. Hydrogen Energy 33, 4265 (2008)

[27] P. Reyes, H. Rojas, J.L.G. Fierro, J. Mol. Catal. A. Chemical 203, 203 (2003).

[28] A.A. Ismail, H. Matsunaga, Chem. Phys. Lett. 447,74 (2007).

[29] Y. Liu, X. Wang, F. Yang, X. Yang, Microporous and Mesoporous Materials 114, 431 (2008).

[30] H. Bönnemann, G. Braun, J. Chem. Eur. 3, 1200 (1997).

[31] H. Zhang, G. Wang, D. Chen, X. Lv and J. Li, Chem. Mater., 20, 6543 (2008).

[32] F. Fresno, M. D. Hernandez-Alonso, D. Tudela, J. M. Coronado, J. Soria Appl. Catal. B 84, 598 (2008) .

[33] S. Suárez, J.M. Coronado, R. Portela, J.C. Martín, M. Yates, P. Avila, B. Sánchez, Environ. Sci. Tech. 42, 5892 (2008).

[34] M. Romero, J. Blanco, B. Sánchez, A. Vidal, S. Malato, A.I. Cardona, E. García, Solar Energy 66, 169 (1999).

[35] W.A. Jacoby, M.R. Nimlos, D.M. Blake, R.D. Noble, C.A. Koval, Environ. Sci. Technol. 28, 1661 (1994).

[36] C. Young, T.M. Lim, K. Chiang, J. Scott, R. Amal, Appl. Catal B: Environ.78,1 (2008. 